\title{
Perspective
}

PERSPECTIVE Actualité en histoire de l'art

Comptes rendus | 2012

\section{Ann Massing, Painting Restoration Before La Restauration: The Origins of the Profession in France, Cambridge, Harvey Miller Publishers, 2012}

Stéphane Loire

\section{(2) OpenEdition \\ Journals}

Édition électronique

URL : http://journals.openedition.org/perspective/3345

DOI : $10.4000 /$ perspective. 3345

ISSN : 2269-7721

Éditeur

Institut national d'histoire de l'art

Référence électronique

Stéphane Loire, «Ann Massing, Painting Restoration Before La Restauration: The Origins of the Profession in France, Cambridge, Harvey Miller Publishers, $2012 »$, Perspective [En ligne], Comptes rendus, mis en ligne le 03 septembre 2013, consulté le 01 octobre 2020. URL : http://journals.openedition.org/ perspective/3345; DOI : https://doi.org/10.4000/perspective.3345 


\section{Ann Massing, Painting Restoration Before La Restauration: The Origins of the Profession in France, Cambridge, Harvey Miller Publishers, 2012}

Stéphane Loire

\section{RÉFÉRENCE}

Ann Massing, Painting Restoration Before La Restauration: The Origins of the Profession in France, Cambridge, Harvey Miller Publishers, 2012. 
1 L'histoire de la restauration des œuvres d'art est un champ de recherche relativement vierge qui a réservé à l'Italie l'essentiel de son attention, en privilégiant souvent des études de cas (une œuvre et sa restauration, un individu, un procédé...). Il est donc particulièrement intéressant de pouvoir signaler les parutions la même année de deux ouvrages ambitieux prenant pour sujet le même foyer géographique, des champs chronologiques identiques et des sources documentaires largement communes, dans des approches synthétiques : elles illustrent assez bien ce que Noémie Étienne qualifiait avec justesse de "crise de croissance de ce domaine de recherche [l'histoire de la

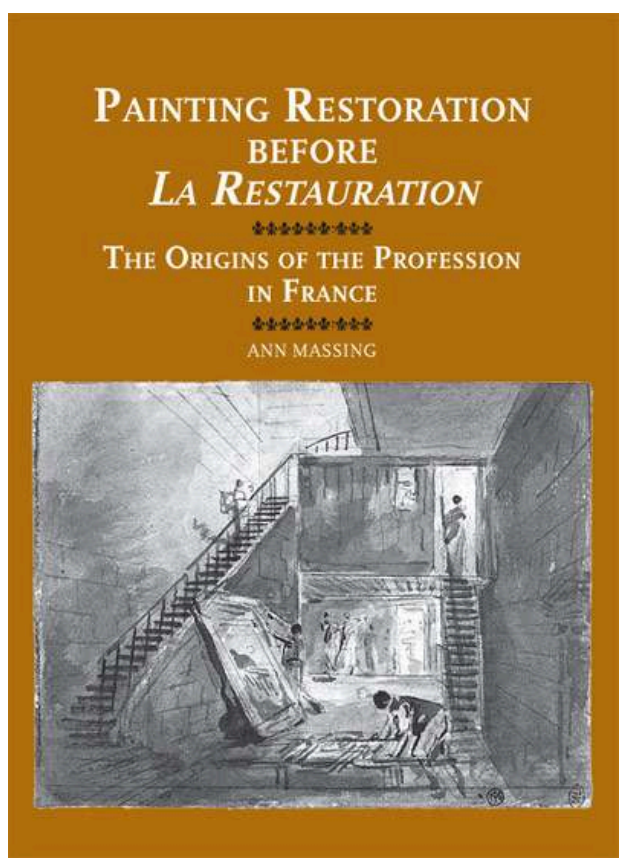
restauration], semblable à celle qu'a

connu, vingt ans auparavant, l'histoire des collections » (voir Étienne, 2012). La figure du restaurateur constitue ici le sujet principal et l'auteur a donné une histoire complète de la restauration des peintures des collections royales puis du Louvre devenu musée, depuis le $\mathrm{xVI}^{\mathrm{e}}$ siècle jusqu'à la chute de l'Empire. Selon un récit rigoureusement chronologique, des chapitres très détaillés sont consacrés à l'activité des principaux responsables des interventions sur ces œuvres (Robert et Jean-Michel Picault, la famille Godefroy, les Hacquin), tandis que d'autres détaillent le rôle de Jean-Baptiste-Pierre Le Brun ou les péripéties de "l'affaire Marin ». Tirant largement parti de la littérature technique contemporaine, l'ouvrage comporte en outre un exposé détaillé sur les matériaux et les techniques de restauration, et donne les transcriptions de nombreux documents d'archives. Très complémentaires, ce volume et celui de Noémie Étienne (voir Étienne, 2012) sont suffisamment différents pour que l'on se réjouisse de leurs parutions presque simultanées. 